\title{
A Personal Tribute
}

I first met Eberhard Mammen when I returned from my armed services commitment in Germany in 1959. Eberhard and his family had just arrived from Germany to join the Department of Physiology at Wayne State University. Dr. Walter Seegers was the chairman of the department. Dr. Seegers' reputation in the field of blood coagulation was unsurpassed and had attracted graduate students from universities throughout the world. Eberhard was one of these, a young, dynamic medical graduate eager to make his mark in this new arena. We reminisced briefly about Germany; his accented English was forceful, a characteristic that was much appreciated by his students and resulted in many teaching awards. Over the next few years, I remained in contact with the department and watched Eberhard's development as a formidable scientist with publications on a variety of topics in hemostasis, from hemophilia and fibrinogen to platelet function in thrombosis. He was appointed to the faculty and with extensive teaching responsibilities later accepted an appointment as dean of the School of Pharmacy. For many years, Dr. Mammen maintained a major reference laboratory that served the needs of hemostatic evaluation on a global basis. As his prominence grew, he continued to publish and served on many editorial boards. He truly became a giant in his field, a recognized leader who demanded the best from his students and colleagues and who was never satisfied with mediocrity.

My fondest memories are of Eberhard lecturing. He had a commanding presence and a well-organized mind. He captured his audience very quickly and made it very difficult for the lecturers who followed. Usually, it was considered best to place Eberhard at the end of a program where he could reawaken listeners after a long series of dry presentations. As with all successful men, Eberhard had the support of a wife who raised their children and stood beside him through pleasant times as well as the more difficult times at the end. Hannah Mammen was often in the area while Eberhard was delivering his talks. I recall on one occasion in Las Vegas running into her in the gaming rooms. She had evaluated all of the slot machines and discovered two that seemed to pay off. With her instructions, I came away ahead instead of suffering the usual loss.

Eberhard's legacy will continue with his children, but even more so, with our remembrance of a very powerful figure who left a large footprint for others to follow.

John A. Penner, M.D., F.A.C.P. ${ }^{1}$
${ }^{1}$ Professor of Medicine, Michigan State University; Chief, Division of Thrombosis, Breslin Professor of Hematology/Oncology (Emeritus), East Lansing, Michigan.

A Tribute to Eberhard F. Mammen, M.D. (1930-2008); Guest Editor, Emmanuel J. Favaloro, Ph.D., M.A.I.M.S.
Semin Thromb Hemost 2008;34:701-702. Copyright (C) 2008 by Thieme Medical Publishers, Inc., 333 Seventh Avenue, New York, NY 10001, USA. Tel: +1(212) 584-4662.

DOI 10.1055/s-0029-1145263. ISSN 0094-6176. 